\title{
Construcció d'una plataforma giratòria per a l'estudi de la força centrípeta
}

\author{
Josep Ametlla Miquel
}

IES Manolo Hugué, Caldes de Montbui

Es descriu la construcció d'un aparell per poder mesurar directament el valor de la força centrípeta, així com altres paràmetres d'un moviment circular uniforme.

\section{MATERIAL}

- Roda posterior de bicicleta, sense el pneumàtic

- Fusta de 60 x $60 \mathrm{~cm}, 5-10 \mathrm{~mm}$ de gruix

- Planxa de suro o bé llistó de fusta complementària

- $10 \mathrm{~cm}$ de llistó gruixut (30 x 40 mm o superior)

- Cinta mètrica de paper (Ikea o similar)

- Politja amb mànec

- Cola de fuster

- Filferro prim (o cordill resistent)

\section{PROCEDIMENT}

1) Marquem les diagonals a la fusta gran

2) Tallem els vèrtexs, a $35 \mathrm{~cm}$ del centre, per aconseguir un octògon

3) Fem un forat al centre de la fusta perquè s'adapti a la roda de bici

4) Amb diverses capes de suro (o trossos de llistonet) construïm 4 gruixos perquè la fusta gran pugui recolzar sobre la roda i quedar horitzontal. Un cop acabats, els enganxem a l'octògon, a la distància adient perquè la roda s'hi recolzi bé (fig. 1).

5) Fem un forat al llistó gruixut (fig. 2) per posar-hi el mànec de la politja. Cal ajustar-ho de manera que la politja quedi a la mateixa altura que el carret que utilitzarem

6) Encolem el Ilistó foradat en una diagonal de la plataforma. La politja ha de quedar just damunt del centre de la roda

7) Enganxem la cinta mètrica a la mateixa diagonal, però a la meitat oposada

8) Al final de la diagonal utilitzada, hi encolem una fusta perquè faci de límit de seguretat
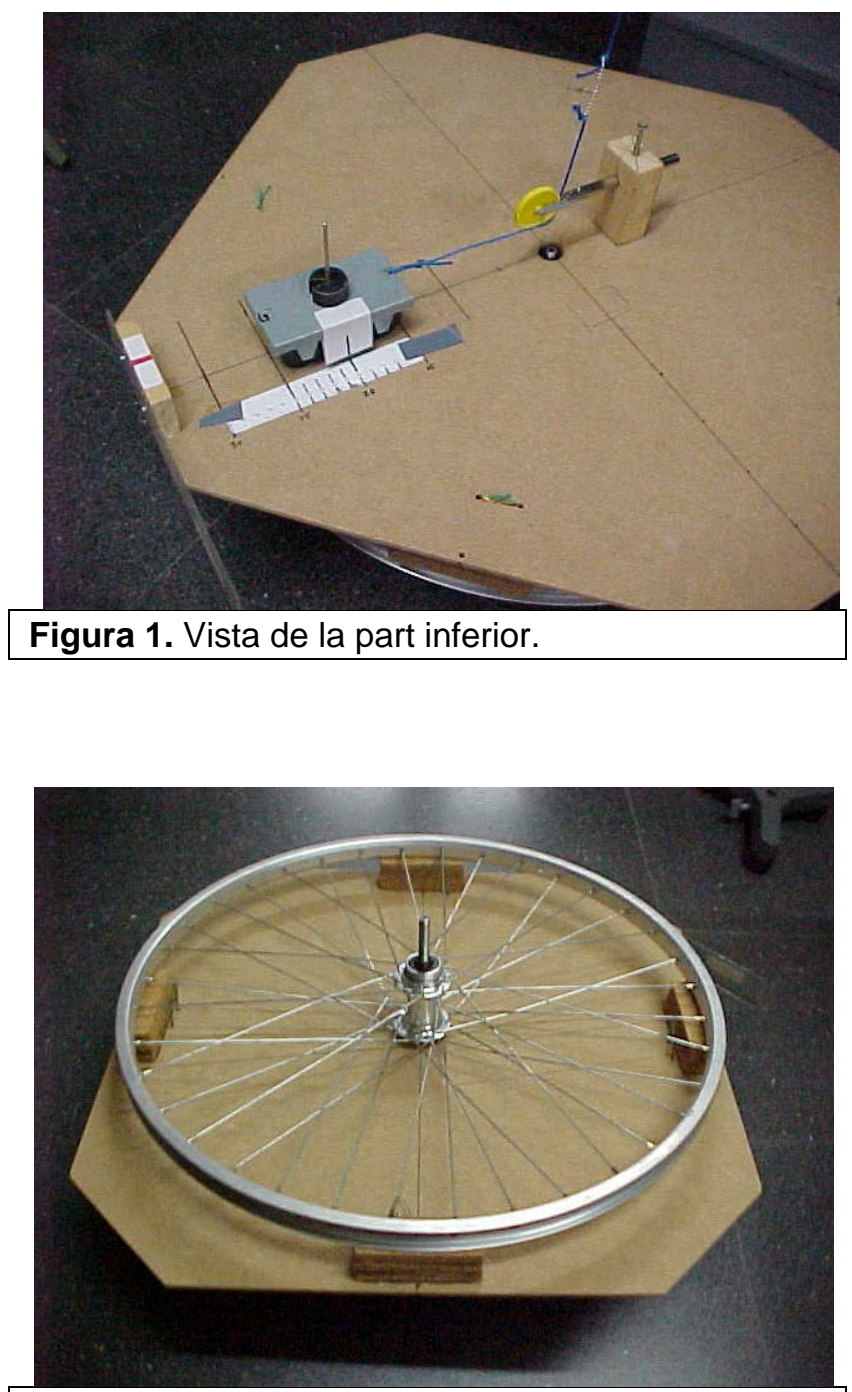

Figura 2. Vista de la part superior. 
9) Fem foradets a la plataforma de fusta i la lliguem amb filferro als radis de la roda de bici. Tot el conjunt ha de quedar unit sòlidament
10) Mitjançant l'espàrrec de la roda, fixem el conjunt a un suport PHYWE o similar

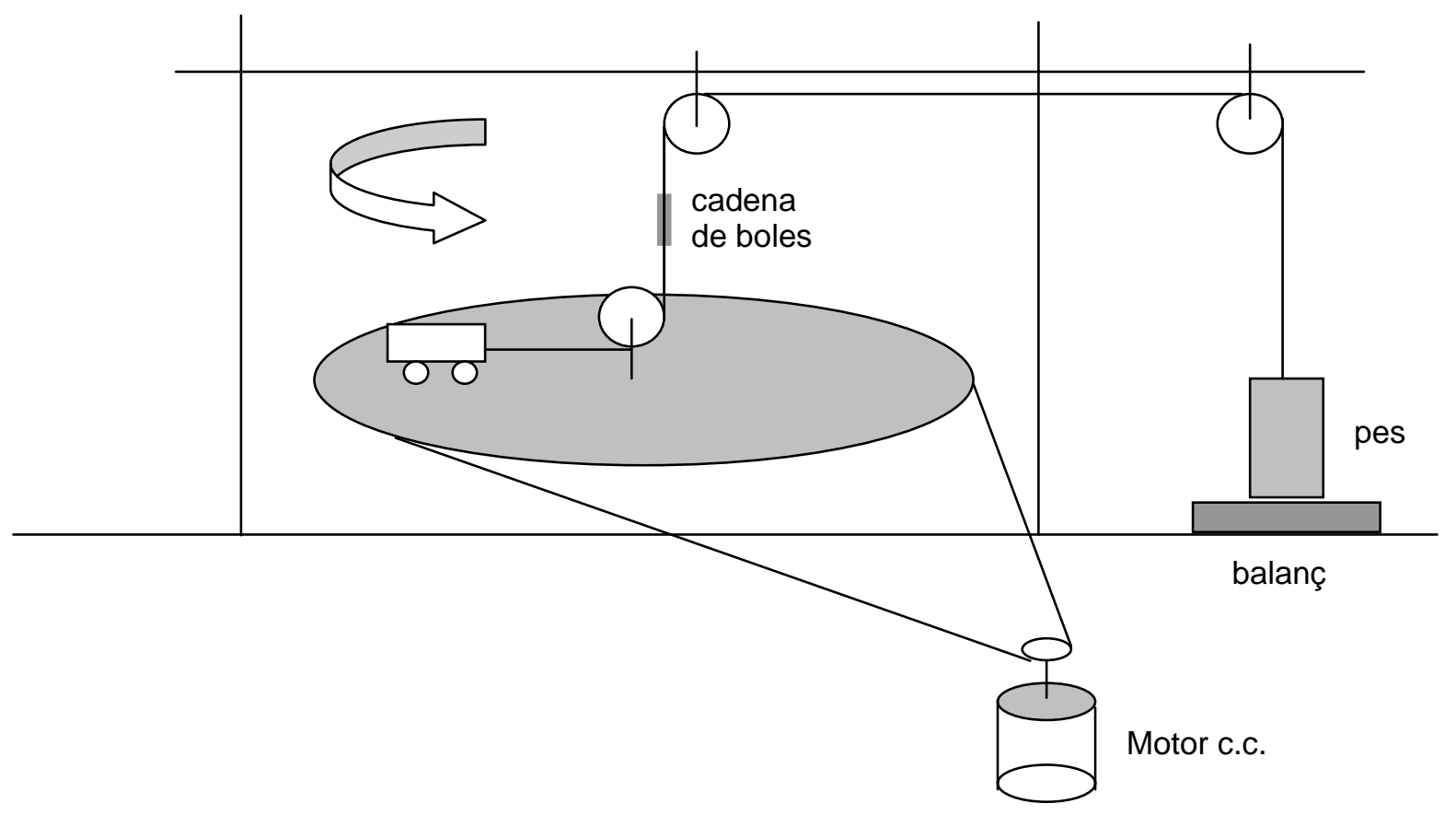

Figura 3. Plataforma giratòria amb els accessoris

- És convenient anivellar bé la plataforma abans de començar les mesures

- Cal utilitzar una font d'alimentació de tensió ajustable per tal de poder regular la velocitat de gir del motor

- Quan la plataforma gira de pressa es fa difícil comptar les voltes. Per això va molt bé disposar un sistema que faci soroll cada vegada que la plataforma dóna una volta. Jo utilitzo un regle de plàstic enganxat a la plataforma, que al girar dóna cops a una capsa de cartró.

- És convenient marcar el centre del carret de manera ben visible (vegeu fig. 2) per mesurar la seva distància al centre de rotació.

- Quan la plataforma gira, el cordill es tensa i s'allarga una mica. Podem ignorar aquest efecte si treballem amb distàncies grans $(25 \mathrm{~cm} 0$ més) i el cordill és poc elàstic. Si es vol més precisió, podem fer el següent: amb la plataforma parada estirem el carret amb la mà fins que la balança marca el mateix que marcava quan estava en rotació. Llavors mesurem la distància al centre sense problemes.

- Si el sistema s'ajusta bé i les mesures es fan amb compte, la discrepància entre la força centrípeta mesurada i els valors que prediu la teoria és petita (menys d'un 5\%)

- Les qüestions proposades al final intenten incidir en algunes dificultats conceptuals dels alumnes, per poder discutir amb ells les respostes donades i així aclarir errors.

\section{ESTUDI DE LA FORÇA CENTRÍPETA}

\section{Objectius}

1. Constatar l'existència d'una força dirigida cap al centre en qualsevol moviment circular i discutir de quins factors depèn.

2. Estudiar la relació entre la força centrípeta i la velocitat angular.

3. Discutir què mesura una balança electrònica i la relació de forces sobre l'objecte situat al seu damunt.

\section{Material}

- Plataforma giratòria

- Motor de c.c. de $12 \mathrm{~V}$ o similar, amb politja

- Alimentació de c.c. de tensió regulable 
- Corretja de transmissió (pot ser 2,5 m de cordó elàstic)

- 3 suports, 1 barra horitzontal i 3 politges

- Carret amb poc fregament PHYWE o similar i peses de $50 \mathrm{~g}$

- Cordill. És convenient usar un cordill que no sigui massa prim i que no s'allargui gaire sota tensió

- Cadeneta de boles (10 cm de la més prima que trobeu), per desacoblar el moviment de rotació

- Balança electrònica de 600 g de capacitat (mínim)

- Ampolla d'aigua (o similar) de 0,5 L de capacitat. De fet es pot utilitzar qualsevol objecte que tingui una massa adequada a la nostra balança

- Cronòmetre

\section{Procediment operatiu}

\section{A) Muntatge}

1. Munta la plataforma giratòria, el motor de corrent continu i connecta'l amb la plataforma mitjançant la corretja de transmissió.

2. Munta els suports amb les politges, de tal manera que una politja estigui just damunt del centre de la plataforma i l'altra damunt de la balança (fig. 3).

3. Omple l'ampolla amb 0,5 L d'aigua (aprox.).

4. Colloca el carret, amb una pesa de $50 \mathrm{~g}$, damunt la plataforma i lliga'l a l'ampolla d'aigua mitjançant el cordill i la cadena de boles. El cordill ha de passar per les politges (fig. 3).

5. Engega la balança.

6. Situa l'ampolla damunt de la balança i regula tot el sistema de tal manera que el carret, al tensar una mica el cordill, quedi a uns 20 o 25 $\mathrm{cm}$ de l'eix de gir.

\section{B) Mesures}

7. Anota la indicació de la balança quan la plataforma no gira. Amb això podrem saber el pes de l'ampolla d'aigua.

8. Engega el motor a baixa velocitat. Cronometra 10 voltes de la plataforma giratòria. Anota la indicació de la balança a la taula 1.

9. Puja una mica la velocitat del motor. Cronometra 10 voltes. Anota la indicació de la balança.

10. Repeteix el procés per diferents velocitats de gir fins a la màxima. Compte! Si la balança marca menys de $100 \mathrm{~g}$, redueix la velocitat de gir!

La tensió del cordill és precisament la força centrípeta que actua sobre el carret. Aquesta força centrípeta la podem determinar de dues maneres:

PRIMERA: La podem mesurar amb l'ajut de la indicació de la balança

SEGONA: La podem calcular amb la fòrmula utilitzant la taula 2 .

$$
\mathrm{F}_{\mathrm{c}}=\mathrm{m} \omega^{2} \mathrm{r}
$$

\begin{tabular}{|c|c|c|c|c|}
\hline $\begin{array}{c}\text { temps } 10 \text { voltes } \\
(\mathrm{s})\end{array}$ & $\mathrm{T}(\mathrm{s})$ & $\omega(\mathrm{rad} / \mathrm{s})$ & Radi de gir $(\mathrm{cm})$ & $\begin{array}{c}\text { Indicació balança } \\
(\mathrm{g})\end{array}$ \\
\hline & & & & \\
\hline & & & & \\
\hline
\end{tabular}

Taula 1. Per recollir les dades experimentals

\begin{tabular}{|l|l|l|l|l|}
\hline$\omega^{2}$ & $\begin{array}{c}\text { Massa } \\
\text { (carro + pesos) }\end{array}$ & $\begin{array}{c}\text { Radi de gir } \\
(\mathrm{m})\end{array}$ & $\begin{array}{c}\text { Força centrípeta } \\
(\mathrm{N}) \\
\text { (mesurada amb } \\
\text { la balança) }\end{array}$ & $\begin{array}{c}\text { Força centrípeta } \\
(\mathrm{N}) \\
\text { (calculada amb } \\
\left.\mathrm{F}_{\mathrm{c}}=\mathrm{m} \omega^{2} \mathrm{r}\right)\end{array}$ \\
\hline & & & & \\
\hline & & & & \\
\hline
\end{tabular}

Taula 2. Càlcul de la força centrípeta i comparació amb el seu valor experimental 


\section{Qüestions}

1. Dibuixa les gràfiques $\mathbf{F}_{\text {centrípeta }}-\omega$, pels valors mesurats (columna 4 de la taula 2) i pels valors calculats (columna 5) Quina forma tenen?

2. Estudia el grau de discrepància (en \%) entre les dues últimes columnes de la taula 2.
3. Fes un dibuix de les forces que actuen damunt l'ampolla d'aigua. Què indica la balança? Quina relació te això amb la força centrípeta?

4. Dibuixa la trajectòria del carret i les forces que actuen sobre seu.

5. Imagina que quan la plataforma està girant es trenca el cordill. Quina trajectòria seguirà el carret? (Fes-ne un dibuix). 